\title{
Numerical study of earth pressures on rigid pipes with tire-derived aggregate inclusions
}

\author{
P. $\mathrm{Ni}^{1}, \mathrm{X} . \mathrm{Qin}^{2}$ and $\mathrm{Y} . \mathrm{Yi}^{3}$ \\ ${ }^{1}$ Research Fellow, School of Civil and Environmental Engineering, Nanyang Technological University, \\ Singapore 639798, Singapore, E-mail: pengpeng.ni@ntu.edu.sg \\ ${ }^{2}$ PhD Candidate, Institute of Geotechnical Engineering, Southeast University; Jiangsu Key Laboratory of \\ Urban Underground Engineering \& Environmental Safety (Southeast University), Nanjing, \\ Jiangsu 210096, China, E-mail: xiaogang.qin2008@gmail.com \\ ${ }^{3}$ Assistant Professor, School of Civil and Environmental Engineering, Nanyang Technological University, \\ Singapore 639798, Singapore,E-mail: yiyaolin@ntu.edu.sg (corresponding author)
}

Received 03 November 2017, revised 10 January 2018, accepted 08 February 2018, published 22 June 2018

\begin{abstract}
Rigid pipes under high embankments are often installed using the induced trench technique by introducing a compressible zone above the pipe. Made from discarded tires, tire-derived aggregate (TDA) has a high compressibility and is resistant to degradation. A new application, using TDA for induced trench rigid pipes is evaluated. A plane-strain finite element simulation is conducted, in which the constitutive curve of TDA measured from a large-scale compression test is implemented. Comparisons with other compressible materials show that TDA can provide similar benefits of load reduction for rigid pipes. A parametric study is carried out to optimise the design, including the geometry of the TDA zone, the spacing between the pipe and the TDA zone, and the relative stiffness between soil and TDA. Results show that earth pressures around the pipe decrease with the increase of the width of TDA zone but are not influenced significantly by its thickness. In the end, numerical data of the load coefficient for rigid pipes with TDA inclusions are compared with field measurements for other compressible inclusions and two analytical solutions. It is found that existing analytical approaches are applicable to the design of induced trench rigid pipes with TDA inclusions.
\end{abstract}

KEYWORDS: Geosynthetics, Tire-derived aggregate (TDA), Induced trench, Rigid pipe, Soil arching, Numerical modelling, High embankment

REFERENCE: Ni, P., Qin, X. and Yi, Y. (2018). Numerical study of earth pressures on rigid pipes with tire-derived aggregate inclusions. Geosynthetics International, 25, No. 5, 494-506. [https://doi.org/ 10.1680/jgein.18.00013]

\section{INTRODUCTION}

It is inevitable that pipes need to be installed under high embankments $(>10 \mathrm{~m})$, especially in a valley region (Oshati et al. 2012; McGuigan et al. 2016; Meguid et al. 2017a). Rigid pipes are generally chosen under high fills, considering the embankment loads and the ease of construction. However, for a rigid pipe buried directly under high fills (i.e. positive projecting conduit) as shown in Figure 1a, the overburden pressure could be increased significantly compared with the prism load due to the negative arching effect. This is because the soil prism above the pipe deforms less than the adjacent soil, and the shear force mobilised between soil columns acts to increase the load (Moore 2001). Alternatively, a pipe can be installed in a trench with loose soil as backfill (i.e. negative projective conduit) as presented in Figure $1 \mathrm{~b}$ (Tien 1996), where the loose soil inside the trench settles more than the natural ground outside the trench. Hence, the mobilised shear will decrease the overburden pressure acting on the pipe due to the positive arching effect (Moore 2001). However, constructing a trench with loose backfill materials under high embankments is often impractical. The induced trench conduit is therefore proposed to introduce the positive arching effect for soils above the pipe by adding a compressible zone (Figure 1c), allowing the overburden pressure to be reduced (Kang et al. 2007, 2008; McAffee and Valsangkar 2008; Kim et al. 2010; McGuigan and Valsangkar 2010).

Some case histories of induced trench rigid pipes under high embankments reported in the literature are summarised in Table 1. It is seen that the pipe diameter $\left(B_{\mathrm{c}}\right)$ generally varies from about $1 \mathrm{~m}$ to $3.6 \mathrm{~m}$. The fill height of embankments can be as high as $10-25 \mathrm{~m}$. A zone of compressible material of limited size (a thickness of $0.5-1.5 B_{\mathrm{c}}$ and a width of $1.0-2.1 B_{\mathrm{c}}$ ) is often introduced 


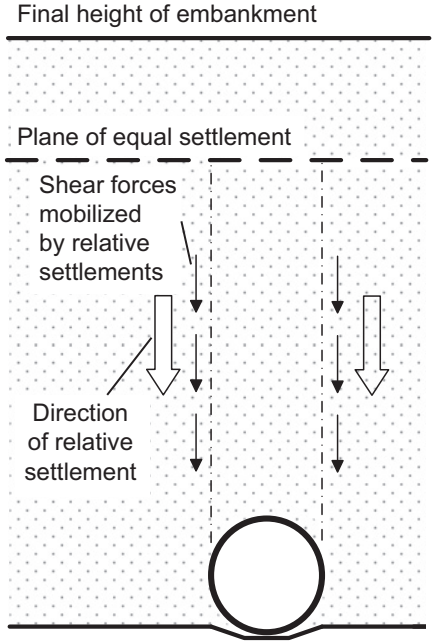

(a)

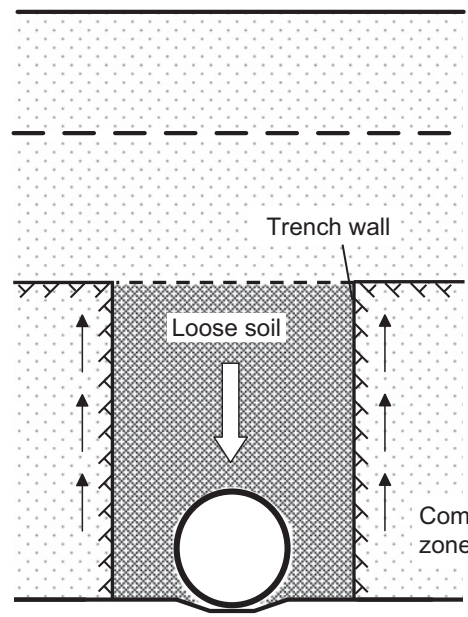

(b)

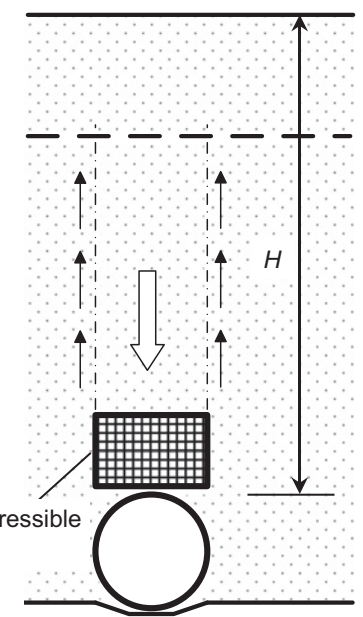

(c)

Figure 1. Simplified arching mechanisms for soil-pipe interaction systems of: (a) positive projecting conduit; (b) negative projective conduit; (c) induced trench conduit

Table 1. Case histories of induced trench rigid pipes under high embankments

\begin{tabular}{|c|c|c|c|c|c|c|}
\hline \multirow[t]{2}{*}{ Shape } & \multirow{2}{*}{$\begin{array}{l}\text { Pipe diameter/ } \\
\text { size }(\mathrm{mm})\end{array}$} & \multicolumn{2}{|c|}{ Embankment } & \multirow{2}{*}{$\begin{array}{l}\text { Compressible } \\
\text { layer thickness } \\
(\mathrm{mm})\end{array}$} & \multirow{2}{*}{$\begin{array}{l}\text { Compressible } \\
\text { material }\end{array}$} & \multirow[t]{2}{*}{ Reference } \\
\hline & & Height (m) & Unit weight $\left(\mathrm{kN} / \mathrm{m}^{3}\right)$ & & & \\
\hline Circular & $2100-2500$ & 11.0 & N/A & $1000-1200$ & Straw \& Polystyrene & Sladen and Oswell (1988) \\
\hline Circular & 1952 & 14.0 & 19.7 & 500 & EPS & Vaslestad et al. (1993) \\
\hline Circular & 1714 & 15.0 & 20 & & & \\
\hline Box & $2000 \times 2550$ & 23.0 & 20 & & & \\
\hline Circular & 900 & 11.8 & 21.3 & 580 & Sawdust & McAffee and Valsangkar (2008) \\
\hline Circular & 3000 & 19.4 & 19.6 & 2750 & Sawdust & Parker et al. (2008) \\
\hline Box & $7900 \times 4900$ & 17.4 & 19 & $50-300$ & EPS & Gu et al. (2009) \\
\hline Circular & 3660 & 21.7 & 21 & 3000 & Sawdust & $\begin{array}{l}\text { McGuigan and Valsangkar } \\
\text { (2011b) }\end{array}$ \\
\hline Box & $2743.2 \times 2438.4$ & 16.46 & N/A & 610 & EPS & Sun et al. (2011) \\
\hline Box & $2600 \times 3600$ & 25.1 & 21 & 2500 & Straw & Oshati et al. (2012) \\
\hline N/A & N/A & 9.0 & $20-22$ & $600-900$ & Geogrid & El Naggar et al. (2015) \\
\hline
\end{tabular}

above the pipe to allow the mobilisation of differential settlement between the prism soil and the adjacent soil, resulting in reduced overburden pressures acting on the pipe due to the positive arching effect (McGuigan et al. 2016; Witthoeft and Kim 2016). Different compressible materials have been employed in the past, including baled straw (Sladen and Oswell 1988), sawdust (McAffee and Valsangkar 2005; Parker et al. 2008), leaves, woodchips, geogrid (Turan et al. 2013; Ahmed et al. 2015; El Naggar et al. 2015), geocell (Mehrjardi et al. 2012, 2013; Hegde and Sitharam 2015), and expanded polystyrene (EPS) geofoam (Vaslestad et al. 1993; Liu 2004; Gu et al. 2009; Jiang 2010; Bartlett et al. 2015).

Rubber tires are being discarded increasingly every year, which creates environmental problems if they are not disposed of properly. The tire recycling industry can consume a certain number of discarded tires to manufacture rubber products of tire-derived aggregate (TDA), and some of them have been successfully used as a lightweight fill material to replace natural aggregates (Lee et al. 1999; Youwai and Bergado 2003; Zornberg et al. 2004; Rowe and McIsaac 2005; Shalaby and Khan 2005;
Yoon et al. 2006; Mills and McGinn 2010; Rezaei et al. 2012). Besides, it has been proven that TDA is costeffective compared to other lightweight fill materials, such as EPS (GC 2008). The consumption of TDA can also ease the environmental issues associated with the storage of discarded tires. TDA is highly compressible (Yang et al. 2002; Rowe and McIsaac 2005; Wartman et al. 2007). For induced trench installation, the high deformability of TDA becomes an advantage, which can induce larger differential settlement between the soil prism above the pipe and the adjacent soil, thereby leading to the positive arching effect to reduce earth pressures. TDA also shows a good resistance to degradation. The durability of TDA has been demonstrated from more severe working environments, including the use of TDA as drainage materials under perforated leachate collection pipes (Rowe and McIsaac 2005), and as an intermediate insulation layer for ground source heat pump pipes (Rezaei et al. 2012). Hence, it would be very interesting to investigate the possibility of using TDA as a compressible material for induced trench rigid pipes. The ASTM D6270 design specification classifies TDA into two types: Type A has 
smaller particle size, and is generally used as insulation materials for road projects or fill materials for retaining walls, while Type B is mainly used as embankment fill. Due to the limited size of the compressible zone above an induced trench rigid pipe, Type A TDA seems to be suitable for use as a compressible material since it has a smaller particle size. A layer of geotextile can be used to wrap around the TDA zone to prevent migration of soils to the voids between TDA particles, similar to the application of TDA to embankment fills (Yi et al. 2015).

Jean and Long (1990) conceived the original idea of using old tires in the compressible zone for induced trench installations. They investigated two field cases of culverts in France using soil-tire mixture to induce positive arching above the structure. However, it only produced a load reduction of $80-90 \%$, which is far less significant than the corresponding value of about $30 \%$ using other compressible materials. Recently, Meguid and Youssef (2018) conducted a series of small-scale $(1.4 \mathrm{~m} \times 1.0 \mathrm{~m} \times 0.45 \mathrm{~m})$ laboratory tests on rigid pipes with a pure TDA inclusion, and found that the average measured earth pressure above the pipe crown was as low as $30 \%$ of the overburden pressure for installations with granular backfills. The observations of the performance of induced trench rigid pipes with soil-tire mixture and pure TDA inclusions are not consistent. It deserves to further demonstrate whether pure TDA can be successfully used for induced trench installations.

Hence, this study employs a plane-strain numerical model to investigate the potential of using pure TDA as the compressible material for induced trench rigid pipes under high embankments. The boundary effects associated with the model size of small-scale tests can be minimised in the numerical simulation. First, the effectiveness of the numerical model is evaluated against small-scale testing data of a rigid pipe with a TDA inclusion, as well as field measurements of earth pressures acting on a rigid pipe with an EPS inclusion. The effect of the TDA inclusion on load reduction is further compared with EPS. A parametric study is then conducted to optimise the design of induced trench rigid pipes with a TDA inclusion, such as the width and thickness of the TDA zone, the spacing between the pipe and the compressible zone, and the relative stiffness between soil and TDA. In the end, numerical results of the load coefficient for TDA are compared with field measurements within other compressible materials and calculations obtained from two existing analytical solutions.

\section{NUMERICAL MODELLING}

\subsection{Geometry of the problem}

In the present study, the effect of load reduction on rigid pipes by a compressible overlain layer is investigated numerically under the plane-strain condition using the general-purpose finite element code ABAQUS. Figure 2 illustrates the definition of parameters used for the planestrain model of an induced trench rigid pipe, where $H$ represents the embankment elevation above the pipe,

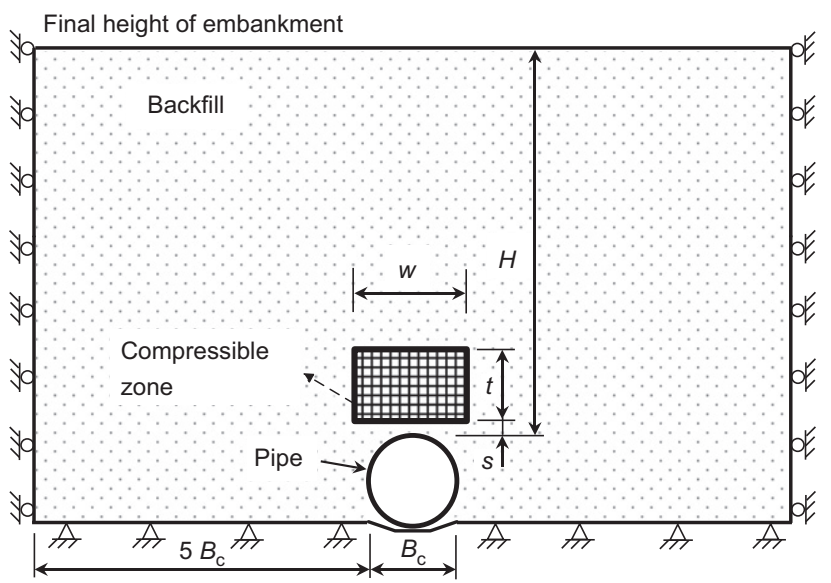

Figure 2. Definition of parameters for a pipe installed using the induced trench method

$B_{\mathrm{c}}$ denotes the pipe diameter, $s$ is the spacing between the pipe and the compressible zone, and $w$ and $t$ are the width and thickness of the compressible zone, respectively.

The model-scale tests of Meguid and Youssef (2018) on induced trench rigid pipes with a TDA inclusion are used to assess the performance of the numerical model. A steel model pipe with a diameter of $B_{\mathrm{c}}=0.15 \mathrm{~m}$ was instrumented with tactile sensors. A TDA zone with a width of $0.4 \mathrm{~m}$ and a thickness of $0.3 \mathrm{~m}$ was placed at $0.3 \mathrm{~m}$ above the pipe. The surcharge pressure was applied incrementally up to $50 \mathrm{kPa}$ to simulate the influence of high embankment. Table 2 summarises all geometric and material parameters used in the numerical model.

The effectiveness of the numerical model is also evaluated by the results of earth pressures around an induced trench rigid pipe with a compressible zone of EPS measured from the field test of Vaslestad et al. (1993). A reinforced concrete drainage pipe was installed under a $14 \mathrm{~m}$ high rock-fill embankment in Telemark County, Eidanger, Norway. Standard EPS blocks were placed $0.5 \mathrm{~m}$ above the concrete pipe with a diameter of $B_{\mathrm{c}}=1.95 \mathrm{~m}$ to reduce the overburden pressure. The pipe was placed above a bedding layer of sandy gravel, and the same material was used to $0.5 \mathrm{~m}$ above the top of the pipe. Rock fill was then employed as the remaining fill in the embankment. A monitoring program was launched to record the overburden pressures around the pipe with earth pressure cells and measure the deformation of EPS with settlement tubes. The geometry of the Eidanger case is provided in Table 3 in detail.

\subsection{Materials}

For the model tests, all material parameters reported by Meguid and Youssef (2018) are employed directly. A reinforced concrete pipe must have adequate strength to resist the overburden pressure acting on the pipe, where the maximum crack should be restricted within a width of $0.254 \mathrm{~mm}$ (0.01 inch) (ASTM C655). Vaslestad et al. (1993) did not present any details about the concrete pipe in their field investigation. Therefore, the properties of the concrete pipe are defined following a similar field work of 
Table 2. Parameters for the induced trench rigid pipe tested by Meguid and Youssef (2018)

\begin{tabular}{|c|c|c|c|c|c|c|c|c|c|c|c|c|c|c|}
\hline \multicolumn{5}{|c|}{ Geometry } & \multicolumn{3}{|c|}{ Backfill } & \multicolumn{4}{|c|}{ Inclusion } & \multicolumn{3}{|c|}{ Pipe } \\
\hline $\begin{array}{l}H \\
(\mathrm{~m})\end{array}$ & $\begin{array}{c}B_{\mathrm{c}} \\
(\mathrm{m})\end{array}$ & $\begin{array}{c}w \\
(\mathrm{~m})\end{array}$ & $\begin{array}{c}t \\
(\mathrm{~m})\end{array}$ & $\begin{array}{c}s \\
(\mathrm{~m})\end{array}$ & $\begin{array}{c}\gamma_{\mathrm{s}} \\
\left(\mathrm{kN} / \mathrm{m}^{3}\right)\end{array}$ & $\begin{array}{c}E_{\mathrm{s}} \\
(\mathrm{MPa})\end{array}$ & $\begin{array}{l}v_{\mathrm{s}} \\
(-)\end{array}$ & Material & $\begin{array}{c}\gamma_{\mathrm{c}} \\
\left(\mathrm{kN} / \mathrm{m}^{3}\right)\end{array}$ & $\begin{array}{c}E_{\mathrm{c}} \\
(\mathrm{kPa})\end{array}$ & $\begin{array}{l}v_{\mathrm{c}} \\
(-)\end{array}$ & $\begin{array}{c}\gamma_{\mathrm{p}} \\
\left(\mathrm{kN} / \mathrm{m}^{3}\right)\end{array}$ & $\begin{array}{c}E_{\mathrm{p}} \\
(\mathrm{GPa})\end{array}$ & $\begin{array}{l}v_{\mathrm{p}} \\
(-)\end{array}$ \\
\hline 0.55 & 0.15 & 0.4 & 0.3 & 0.15 & 16.3 & 150 & 0.3 & TDA & 6.2 & 400 & 0.28 & 78.9 & 200 & 0.3 \\
\hline
\end{tabular}

Note: $\gamma$ represents the unit weight; $E$ denotes the modulus of elasticity; $v$ is Poisson's ratio; the subscripts $s, c$ and $p$ refer to the surrounding soil, the compressible material and the pipe, respectively.

Table 3. Parameters for the induced trench rigid pipe tested by Vaslestad et al. (1993)

\begin{tabular}{|c|c|c|c|c|c|c|c|c|c|c|c|c|c|c|}
\hline \multicolumn{5}{|c|}{ Geometry } & \multicolumn{3}{|c|}{ Backfill } & \multicolumn{4}{|c|}{ Inclusion } & \multicolumn{3}{|c|}{ Pipe } \\
\hline $\begin{array}{l}H \\
(\mathrm{~m})\end{array}$ & $\begin{array}{c}B_{\mathrm{c}} \\
(\mathrm{m})\end{array}$ & $\begin{array}{l}w \\
(\mathrm{~m})\end{array}$ & $\begin{array}{c}t \\
(\mathrm{~m})\end{array}$ & $\begin{array}{c}s \\
(\mathrm{~m})\end{array}$ & $\begin{array}{c}\gamma_{\mathrm{s}} \\
\left(\mathrm{kN} / \mathrm{m}^{3}\right)\end{array}$ & $\begin{array}{c}E_{\mathrm{s}} \\
(\mathrm{MPa})\end{array}$ & $\begin{array}{l}v_{\mathrm{s}} \\
(-)\end{array}$ & Material & $\begin{array}{c}\gamma_{\mathrm{c}} \\
\left(\mathrm{kN} / \mathrm{m}^{3}\right)\end{array}$ & $E_{\mathrm{c}}(\mathrm{kPa})$ & $\begin{array}{l}v_{\mathrm{c}} \\
(-)\end{array}$ & $\begin{array}{c}\gamma_{\mathrm{p}} \\
\left(\mathrm{kN} / \mathrm{m}^{3}\right)\end{array}$ & $\begin{array}{c}E_{\mathrm{p}} \\
(\mathrm{GPa})\end{array}$ & $\begin{array}{l}v_{\mathrm{p}} \\
(-)\end{array}$ \\
\hline 14 & 1.95 & 2.0 & 0.5 & 0.5 & 19.7 & 50 & 0.3 & EPS & 0.2 & 2000 & 0.12 & 23.6 & 28.2 & 0.15 \\
\hline- & - & - & - & - & - & - & - & TDA & 7.6 & $200-400$ & 0.28 & - & - & - \\
\hline - & - & - & - & - & - & - & - & Sawdust & 2.6 & 185 & 0.30 & - & - & - \\
\hline
\end{tabular}

Note: $\gamma$ represents the unit weight; $E$ denotes the modulus of elasticity; $v$ is Poisson's ratio; the subscripts $s, c$ and $p$ refer to the surrounding soil, the compressible material and the pipe, respectively.

Parker et al. (2008). The properties of rock fill in the Eidanger case are evaluated based on the approximate empirical method of Hunter and Fell (2003). McAffee and Valsangkar (2004) claimed that it was not necessary to model the compressible material with an advanced constitutive model for induced trench rigid pipes, and a linear elastic model could reproduce the actual stressstrain response of the material. The modulus of elasticity $\left(E_{\mathrm{c}}\right)$ of EPS normally varies from 1.5 MPa (Ertugrul and Trandafir 2011; Ni et al. 2017) to $2.7 \mathrm{MPa}$ (Kang et al. 2008). In this study, a linear interpretation of $E_{\mathrm{c}}$ of 2.0 MPa is used to approximate the stress-strain response of the EPS material employed by Vaslestad et al. (1993). All design parameters of the Eidanger case are presented in Table 3 for use in numerical modelling.

The load reduction efficiency of TDA is evaluated using the numerical model for the Eidanger case. In addition, the impact of an organic compressible material of sawdust is also studied for comparison. The compression behaviour of sawdust measured by McAffee and Valsangkar (2004) follows a linear pattern. Following the work of Parker et al. (2008), the response of sawdust is characterised with an $E_{\mathrm{c}}$ value of $185 \mathrm{kPa}$, a unit weight of $\gamma_{\mathrm{c}}=2.6 \mathrm{kN} / \mathrm{m}^{3}$, and a Poisson's ratio of $v_{\mathrm{c}}=0.3$. Yi et al. (2015) has demonstrated that the compression of TDA measured in the laboratory may be different from that of TDA measured in the field. In order to eliminate the size effect, Meles et al. (2014) conducted large-scale one-dimensional compression tests on TDA, which were compacted to simulate the in situ density conditions. Further study proved that the constitutive model derived from the large-scale tests could be employed to estimate the compression behaviour of TDA in the field (Meles et al. 2016). For the potential application of induced trench rigid pipes, TDA is confined in the compressible zone. The stiffness of the surrounding soil and TDA could differ by two orders of magnitude. Therefore, it is

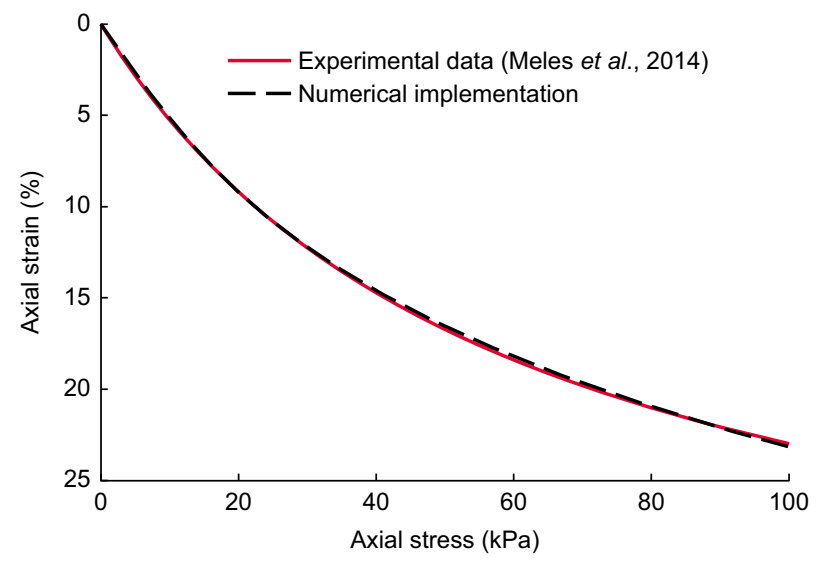

Figure 3. Implementation of the experimentally measured stressstrain curve of Meles et al. (2014) for TDA into numerical program

reasonable to assume that the response of the TDA zone for induced trench rigid pipes can be characterised by the measured constitutive behaviour of TDA in the onedimensional compression test. In this study, the experimental stress-strain behaviour of TDA measured by Meles et al. (2014) as presented in Figure 3 is programmed in the numerical model directly using a hyperelastic model, with input from the uniaxial test data to characterise the nonlinear behaviour of TDA. Meles et al. (2014) also reported that TDA features a unit weight of $\gamma_{\mathrm{c}}=7.6 \mathrm{kN} / \mathrm{m}^{3}$, and a Poisson's ratio of $v_{\mathrm{c}}=0.28$.

\subsection{Modelling strategy}

Following similar soil-pipe interaction studies (Kang et al. 2008; McGuigan and Valsangkar 2011a; Meguid et al. 2017a; Ni et al. 2018), the distance from the lateral boundary to the pipe centreline is selected as five times the pipe diameter to minimise the boundary effects. All lateral 
Table 4. Parameters for the control case

\begin{tabular}{|c|c|c|c|c|c|c|c|c|c|c|c|c|c|c|}
\hline \multicolumn{5}{|c|}{ Geometry } & \multicolumn{3}{|c|}{ Backfill } & \multicolumn{4}{|c|}{ Inclusion } & \multicolumn{3}{|c|}{ Pipe } \\
\hline $\begin{array}{l}H \\
(\mathrm{~m})\end{array}$ & $\begin{array}{l}B_{\mathrm{c}} \\
(\mathrm{m})\end{array}$ & $\begin{array}{l}w \\
(\mathrm{~m})\end{array}$ & $\begin{array}{c}t \\
(\mathrm{~m})\end{array}$ & $\begin{array}{c}s \\
(\mathrm{~m})\end{array}$ & $\begin{array}{c}\gamma_{\mathrm{s}} \\
\left(\mathrm{kN} / \mathrm{m}^{3}\right)\end{array}$ & $\begin{array}{c}E_{\mathrm{s}} \\
(\mathrm{MPa})\end{array}$ & $\begin{array}{l}v_{\mathrm{s}} \\
(-)\end{array}$ & Material & $\begin{array}{c}\gamma_{\mathrm{c}} \\
\left(\mathrm{kN} / \mathrm{m}^{3}\right)\end{array}$ & $E_{\mathrm{c}}(\mathrm{kPa})$ & $\begin{array}{l}v_{\mathrm{c}} \\
(-)\end{array}$ & $\begin{array}{c}\gamma_{\mathrm{p}} \\
\left(\mathrm{kN} / \mathrm{m}^{3}\right)\end{array}$ & $\begin{array}{c}E_{\mathrm{p}} \\
(\mathrm{GPa})\end{array}$ & $\begin{array}{l}v_{\mathrm{p}} \\
(-)\end{array}$ \\
\hline 20 & 3 & 3 & 1.5 & 0 & 19.6 & 20 & 0.3 & TDA & 7.6 & $200-400$ & 0.28 & 23.6 & 28.2 & 0.15 \\
\hline
\end{tabular}

Note: $\gamma$ represents the unit weight; $E$ denotes the modulus of elasticity; $v$ is Poisson's ratio; the subscripts $s, c$ and $p$ refer to the surrounding soil, the compressible material and the pipe, respectively.

walls are constrained in the normal direction (i.e. smooth and rigid boundaries). A bedding layer with a thickness of the maximum between $B_{\mathrm{c}} / 24$ and $76.2 \mathrm{~mm}$ (3 in) must be laid underneath a rigid concrete pipe (ACPA 2004), which essentially produces a yielding foundation. Based on the numerical results of Kang et al. (2008) and the centrifuge testing data of McGuigan and Valsangkar (2010), it has been found that an unyielding foundation could induce a marginal increase in vertical pressures at the pipe crown and invert and a slight decrease in horizontal pressures at the pipe springline compared to a yielding foundation. For induced trench rigid pipes, the magnitude of the vertical pressure is generally concerned during design (Marston 1922; Spangler 1968; Sladen and Oswell 1988; Qin et al. 2017). Therefore, evaluating an induced trench rigid pipe with an unyielding foundation is conservative. The bottom boundary is fixed in all degrees of freedom to simulate the response of induced trench pipe on an unyielding foundation.

The pipe is modelled using elastic two-node beam elements (Kang et al. 2008; McAffee and Valsangkar 2008). The soil and the compressible material are both characterised by elastic three-node plane-strain triangle elements. A bonded interface is modelled between the pipe and the surrounding soil, since it has been demonstrated that different interface friction coefficients could produce comparable results of overburden pressure acting on the pipe with a difference of less than 5\% (Kang et al. 2008; Witthoeft and Kim 2016).

In the field tests or laboratory experiments, it is very hard to measure the vertical pressure acting on the pipe invert accurately owing to the limitation of conventional contact earth pressure transducers (McGuigan and Valsangkar 2010). Recently, Meguid and Youssef (2018) demonstrated that the earth pressure at the invert of buried pipes could be measured successfully using tactile sensors. Numerical modelling provides an alternative to calculate the contact pressure at the base of the pipe. Therefore, the changes of vertical earth pressures acting on the crown and invert of the pipe and horizontal earth pressures on the springline all need to be considered to enable a more uniform pattern of stresses for reducing the ovaling deformation of the pipe (Sladen and Oswell 1988; Witthoeft and Kim 2016).

\subsection{Analysis scheme for parametric study}

In the parametric study, a control case is defined to have $B_{\mathrm{c}}=3 \mathrm{~m}, H=20 \mathrm{~m}, s=0 \mathrm{~m}, w=1.0 B_{\mathrm{c}}$, and $t=0.5 B_{\mathrm{c}}$ with other parameters as tabulated in Table 4 . The choice of the model size follows the commonly used parameters for induced trench rigid pipes as given in Table 1. A typical mesh discretisation of the numerical model for the control case is depicted in Figure 4.

McGuigan and Valsangkar (2011b) indicated that clayey backfill soils, embankment fills and foundation soils could have a modulus of elasticity $\left(E_{\mathrm{s}}\right)$ of 14-20 MPa. McAffee and Valsangkar (2008) used an $E_{\mathrm{s}}$ of $25 \mathrm{MPa}$ to replicate the behaviour of silica sand at the specific relative density and expected pressure range. Kang et al. (2008) modelled the surrounding soil as silty clay compacted to $95 \%$ of maximum density (i.e. CL95 per AASHTO). Kézdi (1974) suggested that for stiff to very stiff silts with low plasticity (i.e. ML or CL per AASHTO), the $E_{\mathrm{s}}$ value could vary from 10 to $30 \mathrm{MPa}$. Therefore, in the control case, an $E_{\mathrm{s}}$ of $20 \mathrm{MPa}$ is chosen to reproduce the elastic deformation characteristics of the surrounding soil.

Based on the control case, a parametric study is conducted following the matrix in Table 5 to optimise the design of induced trench rigid pipes using TDA as compressible material. The effects of the geometry of the compressible zone (i.e. width and thickness), the spacing between the pipe and the compressible zone, and the soil modulus are investigated. The geometry of the compressible zone varies to have a width $(w)$ from $B_{\mathrm{c}}$ to $1.9 B_{\mathrm{c}}$ and a thickness $(t)$ from $0.5 B_{\mathrm{c}}$ to $1.5 B_{\mathrm{c}}$ to cover the practical range (McGuigan et al. 2016; Witthoeft and Kim 2016). McGuigan and Valsangkar (2010) indicated that the spacing $(s)$ between the pipe and the compressible zone should be as small as possible in practice. Four $s$ values from $0 \mathrm{~m}$ to $0.6 \mathrm{~m}$ are studied to check whether the spacing between the pipe and the compressible zone alters the resulting overburden pressure on the pipe. The soil modulus $\left(E_{\mathrm{s}}\right)$ is varied from $10 \mathrm{MPa}$ to $40 \mathrm{MPa}$ to examine how soil arching is influenced by the relative stiffness between soil and TDA.

\section{NUMERICAL RESULTS}

\subsection{Comparison between compressible materials}

In Figure 5, the ratio between vertical pressures at the pipe crown for induced trench rigid pipes with and without TDA inclusions is plotted as a function of the applied surcharge pressure. It can be seen that the numerical model can effectively reproduce the trend of load reduction. As the applied surcharge pressure increases, more differential settlement could be mobilised between the soil 


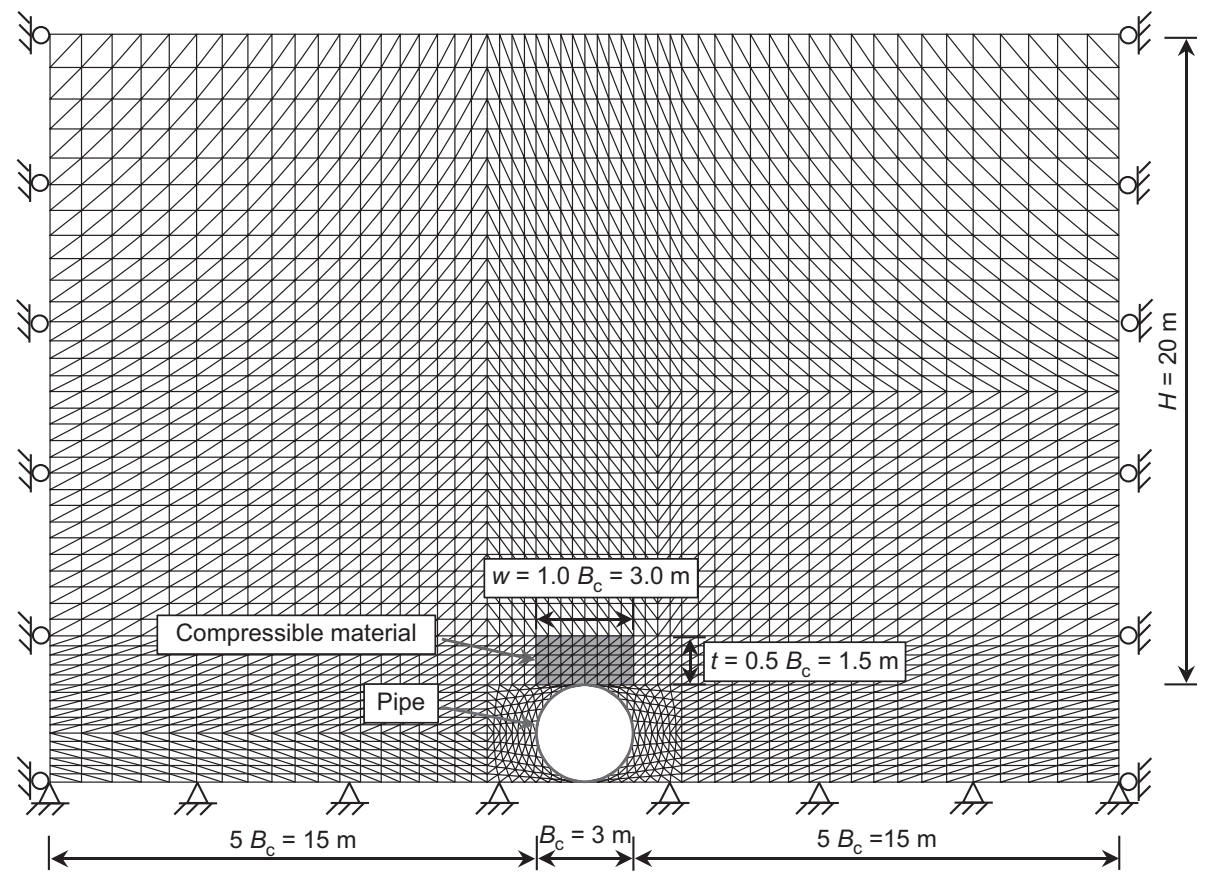

Figure 4. Finite element discretization of the numerical model with a compressible zone of $t=0.5 B_{\mathrm{c}}, w=1.0 B_{\mathrm{c}}$ and $s=0 \mathrm{~m}$

Table 5. Summary of parameters for parametric analysis

\begin{tabular}{|l|l|}
\hline Parameter & Range \\
\hline Width of TDA zone, $w(\mathrm{~m})$ & $3\left(B_{\mathrm{c}}\right), 3.9\left(1.3 B_{\mathrm{c}}\right), 4.8\left(1.6 B_{\mathrm{c}}\right)$, \\
& and $5.7\left(1.9 B_{\mathrm{c}}\right)$ \\
Thickness of TDA & $1.5\left(0.5 B_{\mathrm{c}}\right), 2.4 \mathrm{~m}\left(0.8 B_{\mathrm{c}}\right)$, \\
zone, $t(\mathrm{~m})$ & $3.6\left(1.2 B_{\mathrm{c}}\right)$, and $4.5\left(0.5 B_{\mathrm{c}}\right)$ \\
Spacing between pipe and & $0,0.2,0.4$, and 0.6 \\
TDA zone, $s(\mathrm{~m})$ & $10,20,30$, and 40 \\
Soil modulus, $E_{\mathrm{s}}(\mathrm{MPa})$ & \\
\hline
\end{tabular}

prism above the compressible zone and the adjacent soil, resulting in a more significant positive arching effect and reduced earth pressures acting on the pipe.

Figure 6 illustrates the comparison of earth pressures acting on the induced trench rigid concrete pipe with an EPS inclusion obtained from the field test of Vaslestad et al. (1993) and the present numerical simulation. A theoretical evaluation of earth pressure at the pipe crown as a function of the unit weight of soil $\gamma_{\mathrm{s}}$ and the fill height $H$ is included in Figure 6a. Similarly, a theoretical calculation is also conducted for the overburden earth pressure at the pipe springline by $\gamma_{\mathrm{s}}\left(H+B_{\mathrm{c}} / 2\right)$ as shown in Figure 6b. In general, field measured earth pressures increase with the fill height following a linear pattern. It is interesting that the measured pressure acting on the pipe crown is much smaller than the theoretical calculation, and the reduction of the experimentally measured lateral earth pressure at the pipe springline compared to the theoretical value is less. Numerical results for EPS generally match with those measured in the field. There is a sudden increase of earth pressure at the pipe springline once the embankment fill reaches $9.2 \mathrm{~m}$. This could be induced by pressure inadvertently placed on one side of the pipe at a fill height of 9-10 m (Vaslestad et al. 1993).

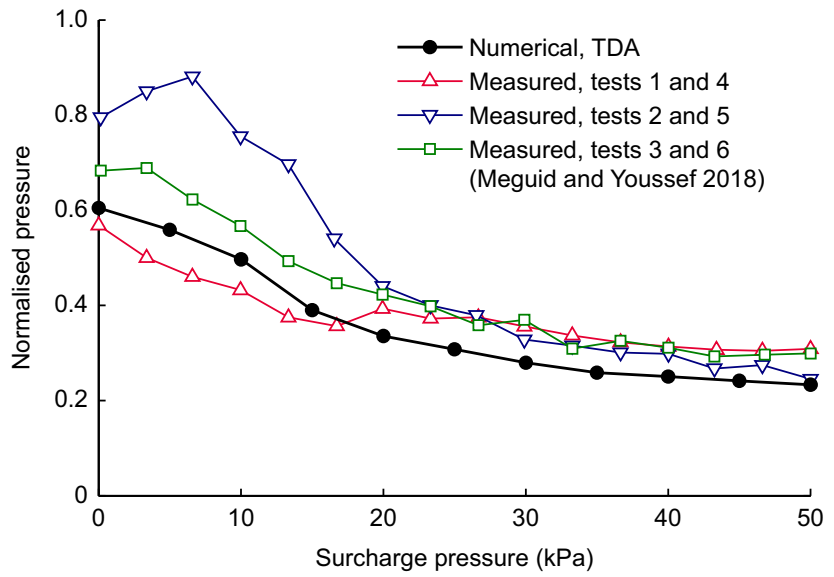

Figure 5. Comparison of earth pressure reduction acting on the crown of the induced trench rigid pipe with a TDA inclusion obtained from finite element modeling and model-scale tests of Meguid and Youssef (2018)

At the end of construction, the lateral earth pressure at the pipe springline is more than twice the vertical pressure at the pipe crown. Vaslestad et al. (1993) claimed that a wider compressible zone should be used to avoid the ovaling deformation of the pipe due to non-uniform pressure distribution.

A direct comparison of earth pressure reduction calculated for TDA, sawdust and EPS is also presented in Figure 6. The results of TDA and sawdust are very similar, but differ from those calculated for EPS. This is probably because the values of the modulus of elasticity for sawdust $(185 \mathrm{kPa})$ and TDA (an interpretation of $200-400 \mathrm{kPa}$ from the stress-strain curve in Figure 3) are not significantly different, whereas the modulus of elasticity of EPS is much higher $(2.0 \mathrm{MPa})$. The efficiency of TDA and sawdust is better than EPS in reducing earth pressures due 


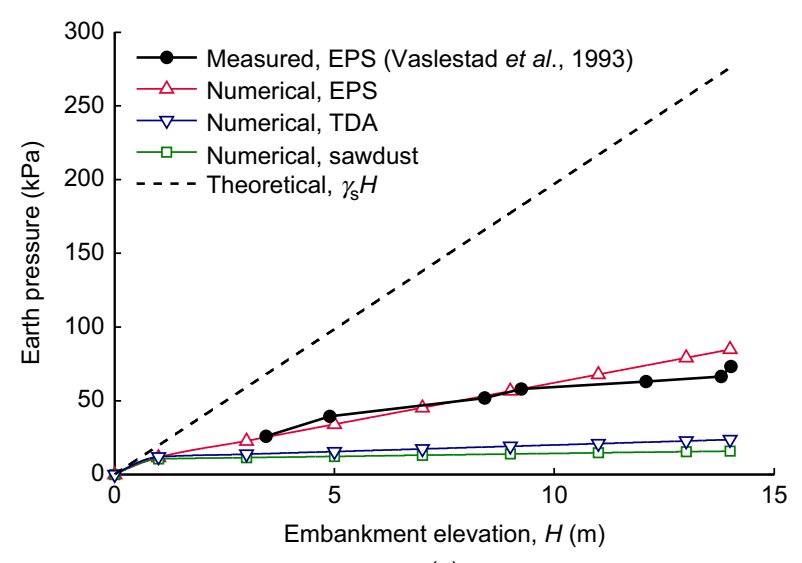

(a)

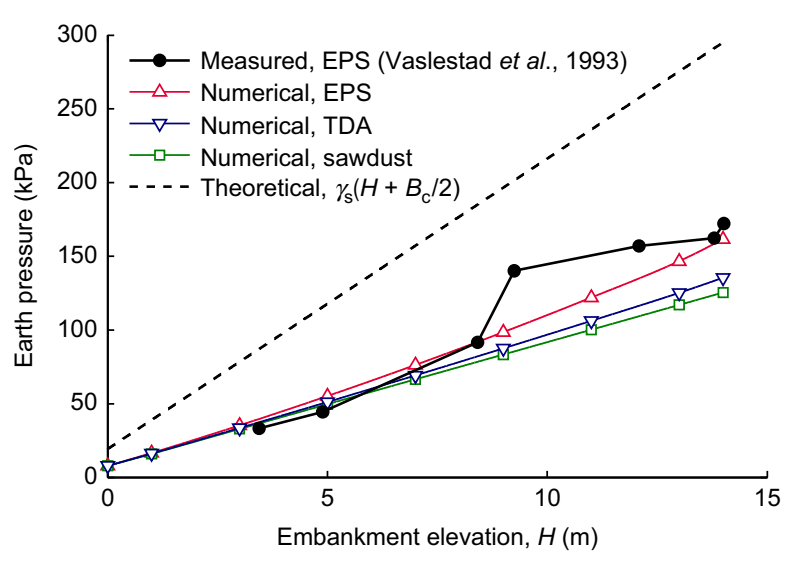

(b)

Figure 6. Earth pressures acting on the induced trench rigid pipe obtained from field monitoring of Vaslestad et al. (1993) for EPS and finite element analyses for EPS, TDA and sawdust: (a) earth pressures at the crown; (b) earth pressures at the springline

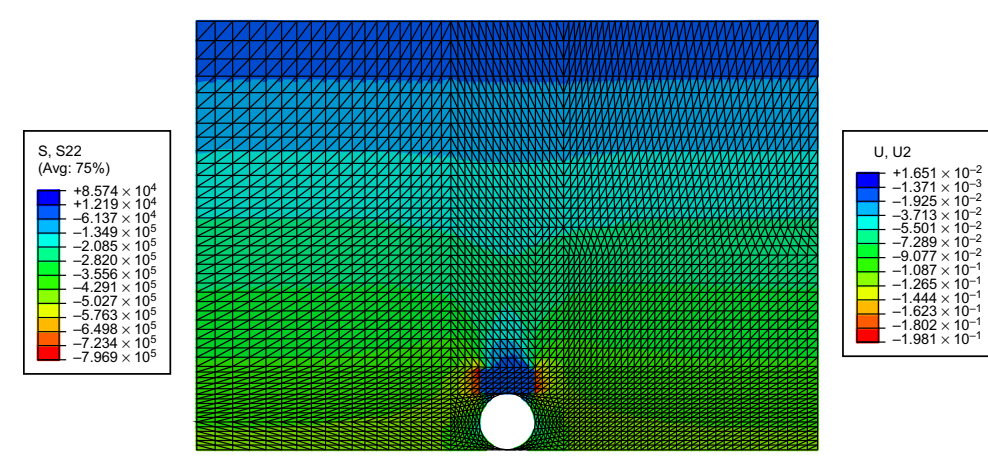

(a)

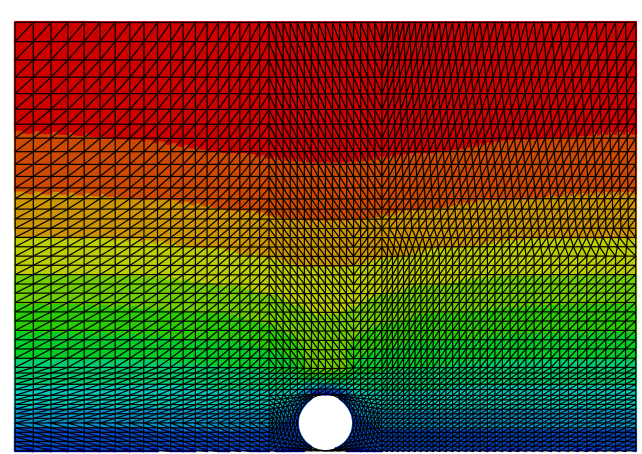

(b)

Figure 7. Results for the numerical model with a compressible zone of $t=0.5 B_{\mathrm{c}}, w=1.0 B_{\mathrm{c}}$ and $s=0 \mathrm{~m}$ illustrating positive arching within the soil above the compressible zone: (a) vertical stress contours (Pa); (b) vertical displacement contours (m)

to the higher value of relative stiffness between the soil and compressible materials, where more positive arching can be mobilized. This demonstrates that a compressible material with a low modulus of elasticity is more beneficial to an induced trench rigid pipe. Considering the good resistance to degradation and the high compressibility with low stiffness, TDA has a great potential for use in applications of induced trench rigid pipes as the compressible material.

\subsection{Normalisation of earth pressures}

The fundamental assumption for induced trench rigid pipes is that the soil prism above the pipe should settle more than the adjacent soil, and the differential settlement between soil columns will mobilise shear forces to provide partial support for the backfill and reduce the overburden pressure. Contours of simulated vertical stress and displacement within the surrounding soil have been used extensively to demonstrate the soil arching mechanism (Parker et al. 2008; Witthoeft and Kim 2016; Meguid and Hussein 2017; Meguid et al. 2017b). In this study, the results of stress and the displacement field are plotted in Figure 7 for the numerical model of the control case with a compressible TDA zone of $t=0.5 B_{\mathrm{c}}, w=1.0 B_{\mathrm{c}}$ and $s=0 \mathrm{~m}$. As an interpretation of Figure 7a, the strain in the TDA zone is approximately $15-20 \%$. The measured strain range as shown in Figure 3 covers a strain level of approximately $23 \%$, which is higher than the maximum compressive strain of TDA calculated in the numerical model. Therefore, the use of the measured nonlinear constitutive behaviour of TDA in the numerical model is effective. It can be seen that the soil prism above the pipe indeed settles more, and less vertical stress is mobilised above the pipe. The pattern of vertical stress and displacement within the soil reflects the formation of positive soil arching. From Figure $7 b$, one can infer that a plane of equal settlement could potentially occur near the ground surface (at least above $15 \mathrm{~m}$ fill).

Figure 8 shows the distribution of vertical pressure along the pipe invert and the top of the TDA zone for the control case. The vertical pressure above the pipe generally follows a parabolic shape, which is consistent with the analytical assumption of Qin et al. (2017) and the centrifuge test results (McGuigan and Valsangkar 2010; Abuhajar et al. 2015). The earth pressure profile obtained from numerical analysis demonstrates the occurrence of the positive arching effect within the soil above the pipe.

For the numerical model with a compressible TDA zone of $t=0.5 B_{\mathrm{c}}, w=1.0 B_{\mathrm{c}}$ and $s=0 \mathrm{~m}$, Figure 9 gives the calculated vertical earth pressures acting on the crown and invert, and the lateral pressures at the springline of the pipe, along with the estimated overburden values from the 
theoretical solution. In Figure 9a, the vertical earth pressure at the same elevation as the pipe crown taken near the lateral boundary is denoted as the free field soil response, which coincides with the theoretically calculated value as expected. It can be seen that TDA can effectively help to reduce the overburden pressure acting on the pipe crown. The inclusion of the TDA zone also produces a reduced earth pressure at the pipe springline compared to the theoretical value (Figure 9b). At the pipe invert, the

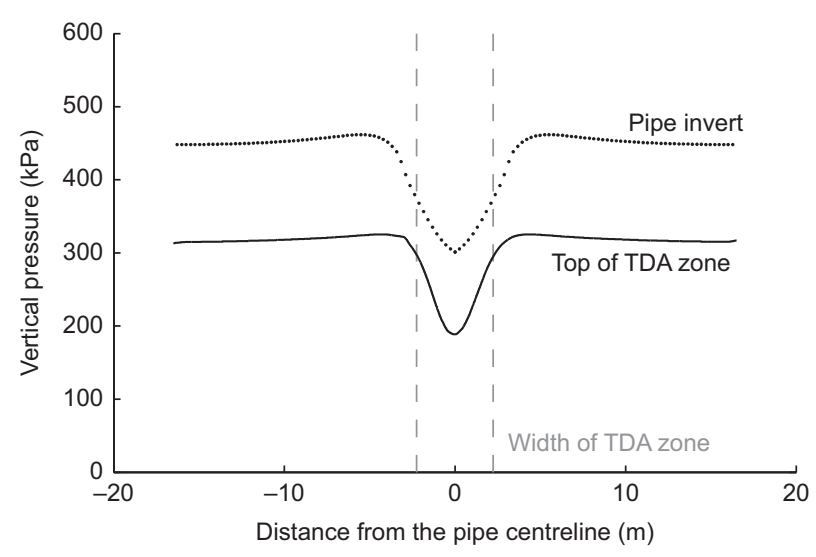

Figure 8. Distribution of vertical pressure along the pipe invert and the top of the TDA zone

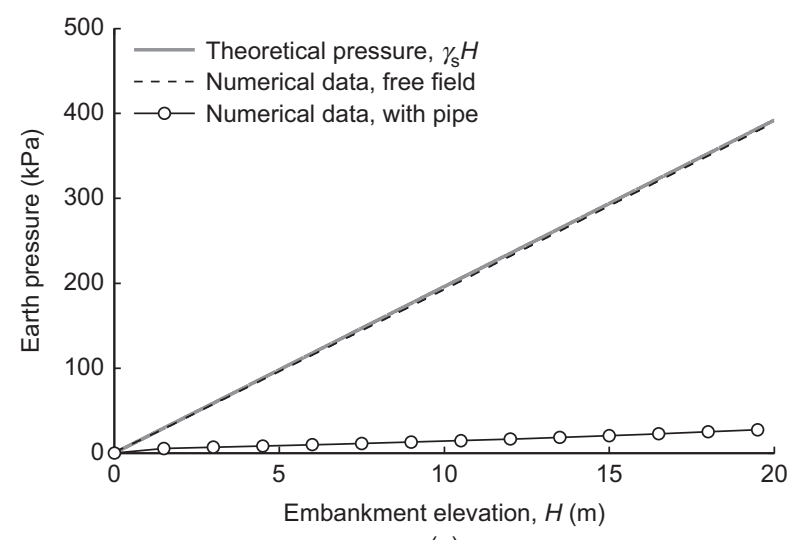

(a)

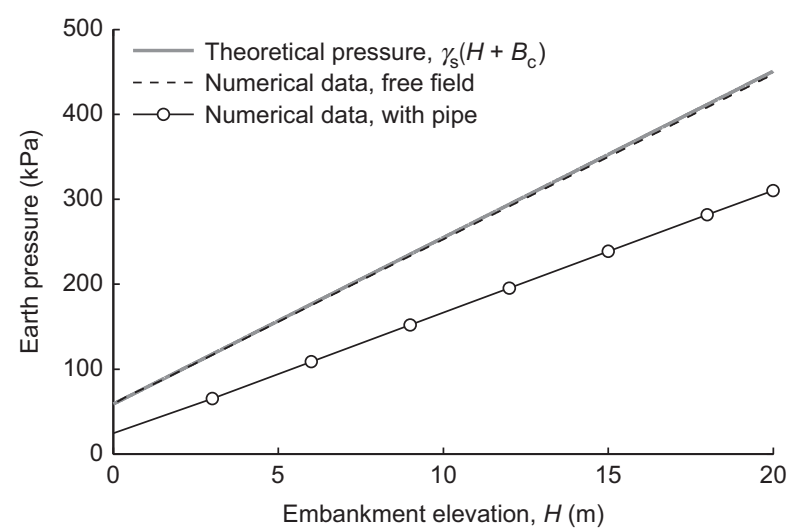

(c) evaluated contact pressure is lower than the theoretical value (Figure 9c). In Figure 9d, the numerically calculated earth pressures are normalised against the corresponding theoretical values to illustrate the efficiency of including a TDA zone above the pipe.

Figure 9d shows that the earth pressure acting on the pipe crown with a TDA inclusion varies from 0.07 to 0.19 times the overburden pressure. This reduction ratio is lower than the observation of Parker et al. (2008) for sawdust, who suggested an approximate range between 0.2 and 0.5. McGuigan and Valsangkar (2010) also reported that the earth pressure on the pipe top with an EPS inclusion should be as low as 0.28 times the overburden. Meguid and Youssef (2018) found that a TDA layer above the pipe could reduce the earth pressure at the pipe crown to $0.28-0.3$ times the overburden. The difference between the present numerical study and the laboratory tests of Meguid and Youssef (2018) might be induced by the different sizes of the compressible zones, as well as the difference in material properties. For the contact pressure at the invert, the theoretical value is scaled by a factor of 0.42 to 0.69 for TDA, which is also less than the suggested value of 0.73 by McGuigan and Valsangkar (2010) for EPS. It can be seen that the reduction of earth pressure at the pipe invert is less than that observed at the pipe crown. This is consistent with the numerical calculations of Kang et al. (2008) and

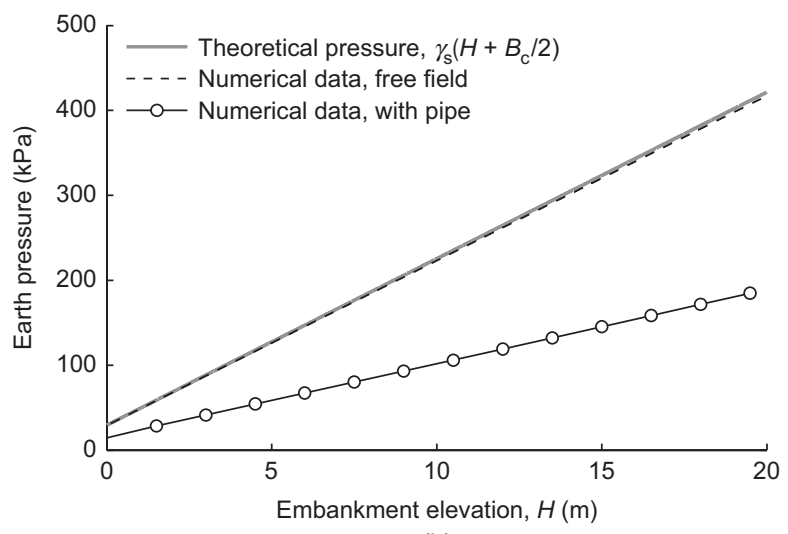

(b)

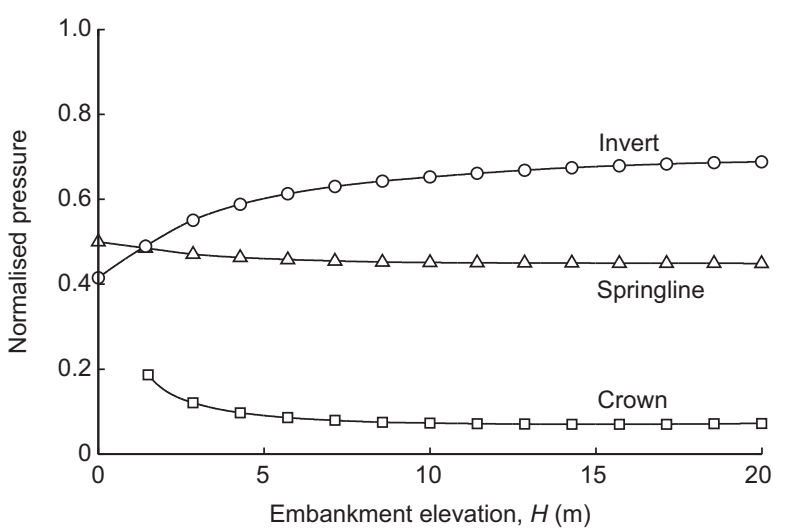

(d)

Figure 9. Calculated earth pressures around the pipe with a compressible zone of $t=0.5 B_{\mathrm{c}}, w=1.0 B_{\mathrm{c}}$ and $s=0 \mathrm{~m}$ : (a) earth pressure at pipe crown; (b) earth pressure at pipe springline; (c) earth pressure at pipe invert; (d) normalized pressure against theoretical pressure versus embankment elevation 
McGuigan and Valsangkar (2010), where the reduced benefit of earth pressure reduction by a compressible zone was attributed to the increased shear stresses (net downward frictional forces) at the soil-pipe interface. The horizontal pressure at the springline is scaled by 0.45 to 0.5 for TDA. McGuigan and Valsangkar (2010) measured the lateral earth pressure at the side to be 0.47 times the mid-height overburden for EPS. Oshati et al. (2012) also calculated the lateral earth pressure as $0.49-0.6$ times the mid-height overburden for straw. A lateral earth pressure coefficient of approximately $K_{0}=0.5$ needs to be included to calculate the horizontal earth pressure at the pipe springline from the mid-height overburden. The observation of the current study coincides with the field tests of McGuigan et al. (2016), where the induced trench installation was found to cause negligible changes in lateral earth pressures at the pipe springline.

\subsection{Results for parametric study}

The calculated results of normalised pressure as a function of the fill height above the pipe crown for different widths $(w)$ of TDA zone are plotted in Figure 10. The increase of $w / B_{\mathrm{c}}$ corresponds to an improved performance of load reduction at the pipe springline and the invert. A higher value of $w / B_{\mathrm{c}}$ could, however, cause a slightly increased earth pressure acting on the pipe crown, which coincides with the calculation of Qin et al. (2017). Generally, the horizontal pressure acting at the pipe springline is larger than the vertical pressure on the pipe crown, which is consistent with the field observation of McAffee and Valsangkar (2008). With the increase of $w / B_{\mathrm{c}}$, the difference in vertical and horizontal pressures becomes smaller, which is beneficial to the pipe by reducing the ovaling deformation of the pipe cross-section (Sladen and Oswell 1988; Vaslestad et al. 1993; Witthoeft and Kim 2016). A separate study of incorporating a much wider width of TDA zone of $w=3.0 B_{\mathrm{c}}$ (not common in practice) was also conducted, and the normalised pressures reduce

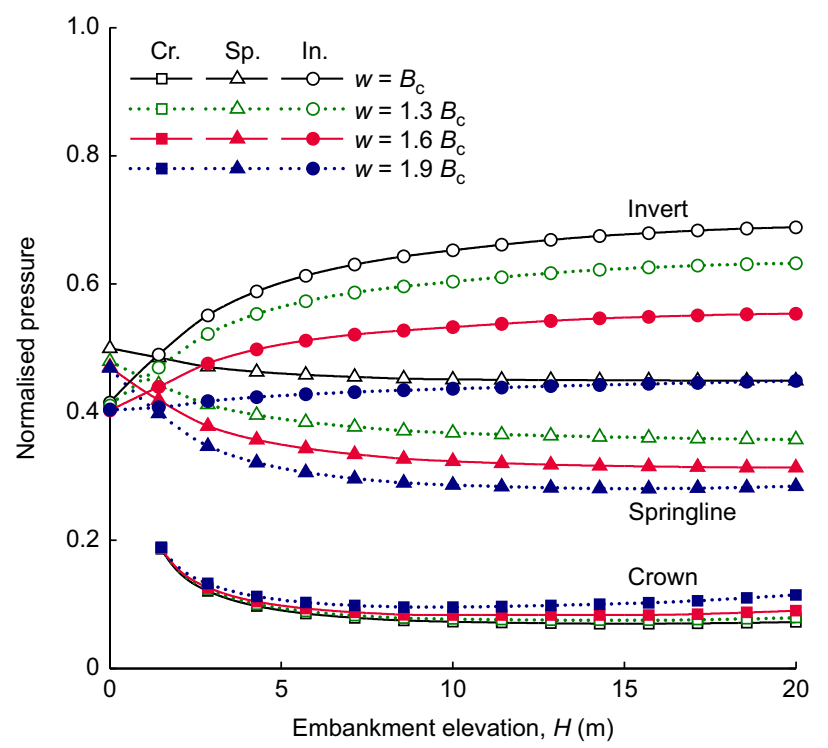

Figure 10. Influence of the width of the TDA zone on normalized pressure continuously with the increase of $w / B_{\mathrm{c}}$, without showing a plateau. The positive arching effect can mobilise the friction forces along the vertical edges between the soil prism above the compressible zone and the adjacent soil to reduce the earth pressure acting on the pipe. When a higher width is used in the compressible zone, the vertical edges move further away from the centreline of the pipe, leading to a reduced proportion of load transferred from the overlying soil column to the pipe. A greater width of the compressible zone should be used in practice to provide the most efficient solution to reduce earth pressures and to produce a more uniformly distributed stress state around the pipe, given economic considerations.

In Figure 11, the variation of normalised pressure acting on the pipe with the height above the pipe crown for different thicknesses $(t)$ of the TDA zone are presented. It can be seen that the changes in $t$ do not influence the pressure significantly. Numerical simulations for induced trench rigid pipes with EPS inclusions (McGuigan and Valsangkar 2010; Meguid et al. 2017a) also demonstrated that the effect of load reduction by the compressible material is insensitive to the choice of $t$ value. This is partially due to the fact that the positive arching effect for induced trench rigid pipes is mobilised by the differential settlement between the prism soil and the adjacent soil. The deformation of the TDA zone is primarily influenced by the applied pressure from the overburden, where an increase of $t$ will cause a reduction of overburden pressure for a fixed fill height. When the overburden pressure reduces, the compressive strain will also decrease. The vertical deformation of the TDA zone is a product of $t$ and the compressive strain. The effects of increasing $t$ and decreasing the overburden pressure could cancel each other out. In addition, the plane of equal settlement could occur at a depth of at least $15 \mathrm{~m}$ above the pipe (Figure 7b). For a small fill height, different $t$ values can still result in a different degree of normalised pressure at the pipe crown. As the fill height increases, the full

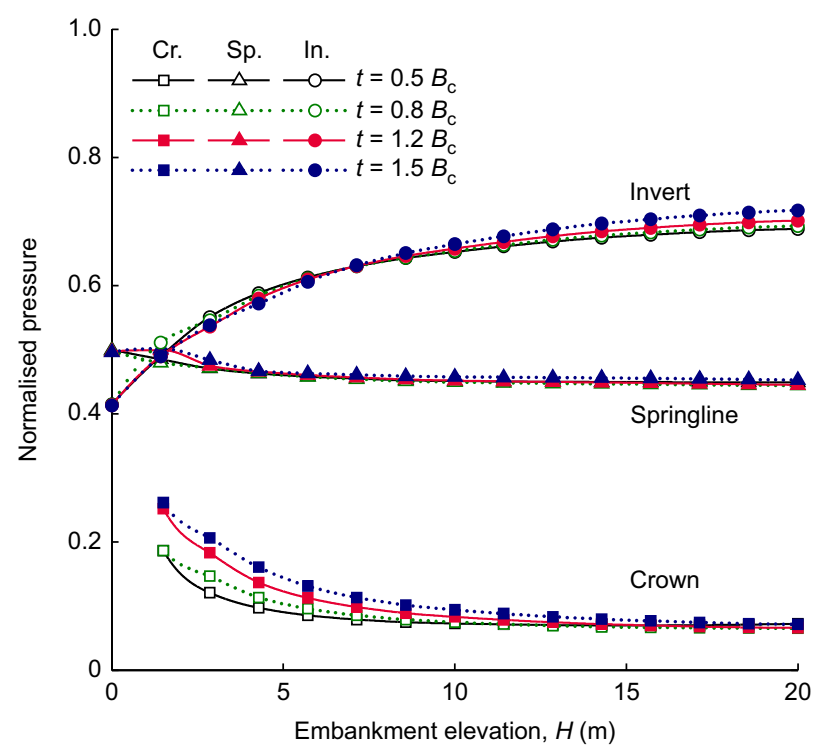

Figure 11. Influence of the thickness of the TDA zone on normalized pressure 
differential settlement between the prism soil and the adjacent soil is mobilised, and the influence of $t$ on normalised pressure diminishes. Therefore, the mobilised arching effect is not significantly affected by the variation of $t$. Qin et al. (2017) included the influence of $t$ in their analytical derivation of earth pressure above an induced trench rigid pipe, and found that the calculated earth pressure is insensitive to $t$ within the range between $t=0.5 B_{\mathrm{c}}$ and $t=1.5 B_{\mathrm{c}}$ as studied in this investigation for practical burial depths. McGuigan and Valsangkar (2010) conducted a series of centrifuge tests and suggested using $t=0.5 B_{\mathrm{c}}$ to optimise the design for induced trench rigid pipes, mostly considering the economic benefits.

The spacing between the pipe and the compressible zone is investigated, and the results for four values of spacing are given in Figure 12. For the lower bound of spacing of $s=0 \mathrm{~m}$, the effect of load reduction is most significant at the pipe crown, but higher pressures are mobilised at the pipe springline. This is probably because a small amount of deflection of TDA zone occurs in the horizontal direction, which alters the stress state at the pipe springline more significantly when the TDA zone is placed closer to the pipe. A higher bound of spacing of $s=0.6 \mathrm{~m}$ can increase the earth pressures at the pipe crown and springline simultaneously. Overall, the most effective configuration to reduce earth pressures around the pipe is to have a spacing of $s=0.2 \mathrm{~m}$. McGuigan and Valsangkar (2010) indicated that a spacing of $s=0.3 \mathrm{~m}$ ( 1 foot) is normally used in practice, but there is no relevant design specification for this quantity. For a given embankment elevation, an increase of spacing above the optimal value of $s=0.2 \mathrm{~m}$ will result in less soil above the compressible zone. Therefore, the overburden pressure reduces and less differential settlement between the soil prism and the adjacent soil will be mobilised. A high value of $s$ will minimise the beneficial effect of the compressible zone on the pipe, since the positive arching effect is

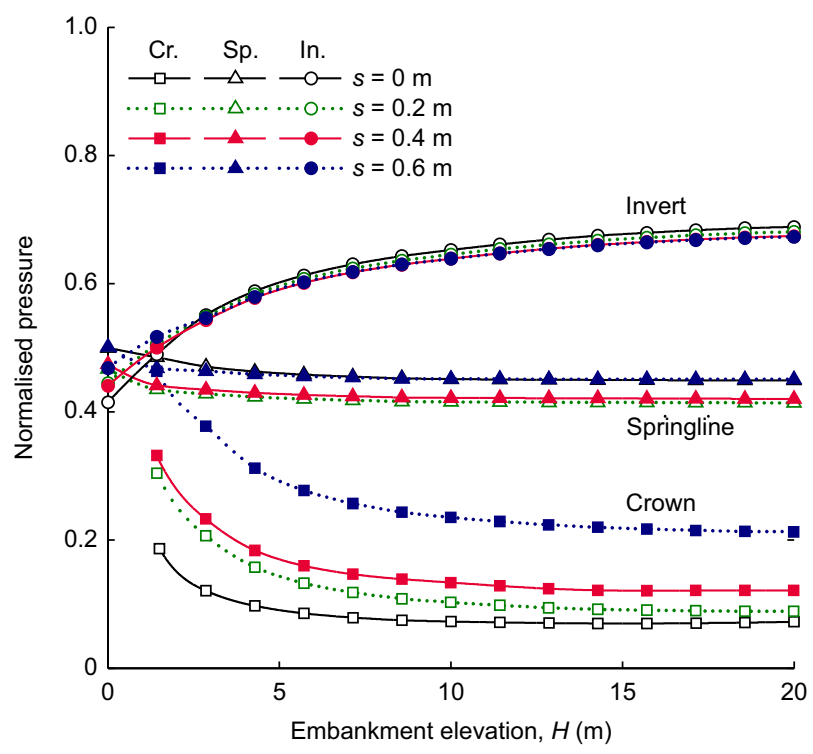

Figure 12. Influence of the spacing between the pipe and compressible zone on normalized pressure

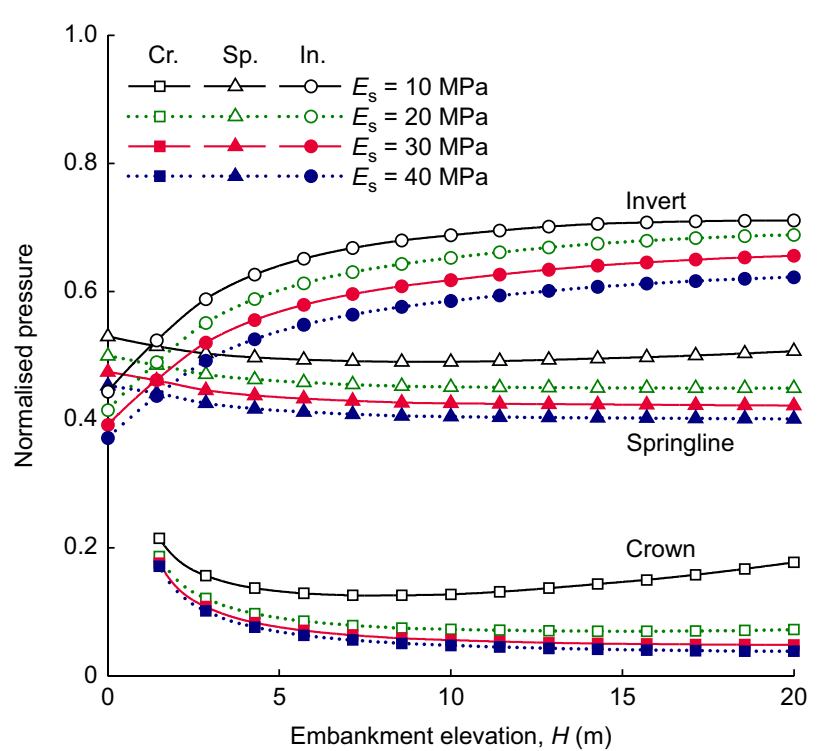

Figure 13. Influence of soil modulus on normalized pressure

diminished. However, when $s=0 \mathrm{~m}$, the horizontal pressure at the pipe springline could be influenced by the stress redistribution within the soil near the pipe. In this investigation, it is therefore suggested that a spacing of $s=0.2-0.3 \mathrm{~m}$ is used in practice.

The effect of relative stiffness between soil and TDA on normalised pressure at different portions of the pipe is depicted in Figure 13. It shows that a higher soil modulus can result in a lower earth pressure acting on the pipe. When the soil has a higher modulus, a more noticeable differential settlement could be mobilised between the soil prism and the adjacent soil correspondingly, which indicates that a larger portion of the prism load is transferred to the adjacent soil. Therefore, a larger relative stiffness between soil and TDA can result in a more significant positive soil arching effect, leading to greater reduction in earth pressures. Special care should be taken with induced trench rigid pipes in less stiff backfills $\left(E_{\mathrm{s}} \leq 10 \mathrm{MPa}\right)$ under a high embankment, since the normalised pressures around the pipe increase with the fill height.

\section{COMPARISON AGAINST ANALYTICAL SOLUTIONS}

It has been previously demonstrated that TDA can be used as a compressible material to have an equivalent effect to other widely used materials for induced trench rigid pipes. It is also worth evaluating whether the existing analytical approaches of the Marston-Spangler theory (Marston 1922; Spangler 1968) and of Qin et al. (2017) can be used to design induced trench rigid pipes with a TDA inclusion.

The Marston-Spangler theory (i.e. Marston's theory) assumes a uniformly distributed vertical stress $\sigma_{\mathrm{v}}$ acting on top of the soil element above the compressible zone. The calculation of $\sigma_{\mathrm{v}}$ is simply carried out as a function of the unit weight of soil $\gamma_{\mathrm{s}}$, the width of the compressible zone $w$, 
and the load coefficient $C_{\mathrm{c}}$ as follows

$$
\sigma_{\mathrm{v}}=C_{\mathrm{c}} \gamma_{\mathrm{s}} w
$$

where the term $C_{\mathrm{c}}$ is dependent on the burial condition of the pipe. A complete condition refers to the case when the height of the equal settlement plane $H_{\mathrm{e}}$ is greater than the fill height $H\left(H_{\mathrm{e}} \geq H\right)$, and an incomplete condition represents the scenario of $H_{\mathrm{e}}<H$ (McAffee and Valsangkar 2008).

$$
\left\{\begin{array}{l}
C_{\mathrm{c}}=\frac{\mathrm{e}^{-2 K \mu(H / w)}-1}{-2 K \mu}, H_{\mathrm{e}} \geq H \\
C_{\mathrm{c}}=\frac{\mathrm{e}^{-2 K \mu\left(H_{\mathrm{e}} / w\right)}-1}{-2 K \mu}+\left(\frac{H-H_{\mathrm{e}}}{w}\right) \mathrm{e}^{-2 K \mu\left(H_{\mathrm{e}} / w\right)}, H_{\mathrm{e}}<H
\end{array}\right.
$$

where $K$ is the lateral earth pressure coefficient and is often assumed as the Rankine active earth pressure coefficient, $K_{\mathrm{a}}$. The parameter $\mu$ represents the friction coefficient of soil.

The Marston's theory has limitations to properly consider the property and geometry of the compressible zone. Qin et al. (2017) proposed a modification to the analysis for induced trench rigid pipes by assuming a parabolic distributed pattern of vertical pressures acting on the soil element above the compressible zone. The vertical pressure above the pipe centreline $\sigma_{\mathrm{v}}$ is still a function $\gamma_{\mathrm{s}}, w$, and $C_{\mathrm{c}}$ as given in Equation 1. The load coefficient $C_{\mathrm{c}}$ is now defined as

$$
\left\{\begin{array}{l}
C_{\mathrm{c}}=\frac{1}{2 m}\left(1-\mathrm{e}^{-2 m H / \beta}\right), H_{\mathrm{e}} \geq H \\
C_{\mathrm{c}}=\frac{1}{2 m}\left[1-\mathrm{e}^{-2 m H_{\mathrm{e}} / \beta}+\frac{2 m\left(H-H_{\mathrm{e}}\right)}{w} \mathrm{e}^{-2 m H_{\mathrm{e}} / \beta}\right], \quad H_{\mathrm{e}}<H
\end{array}\right.
$$

where the parameter $m$ stands for $S K \mu$, and $K$ and $\mu$ preserve the same definition compared to Marston's theory. The term $S$ is called the stress factor and can be expressed by $S=1+1 /(2 \alpha)$. The parameter $\alpha$ is always positive, which affects the shape of the stress distribution. The shape parameter $\alpha$ is taken as 2 in this study following Qin et al. (2017) to provide an approximation for the concave-up shaped stress distribution, which falls within the range of 1.9-3.5 (McGuigan and Valsangkar 2010) and 1.3-3.5 (Kawabata et al. 2006). The force factor $\beta$ can be computed as $\beta=w(1+6 \alpha) /(6 \alpha)$.

Figure 14 shows the comparisons of load coefficient $C_{\mathrm{c}}$ evaluated from numerical simulations for TDA, field measurements for other compressible materials and two analytical solutions. All field measurements include data obtained for sawdust (McAffee and Valsangkar 2008; Parker et al. 2008; McGuigan and Valsangkar 2011b) and EPS (Vaslestad et al. 1993; Liu 2004; Gu et al. 2009; Jiang 2010; Sun et al. 2011) in the compressible zone. It should be noted that comparisons are conducted for a single value of normalised width of $w / B_{\mathrm{c}}=1$. This is because Marston's theory can only provide a calculation for induced trench rigid pipes with a compressible zone where the width is equal to the pipe diameter (Sladen and Oswell 1988; Qin et al. 2017). The numerical values

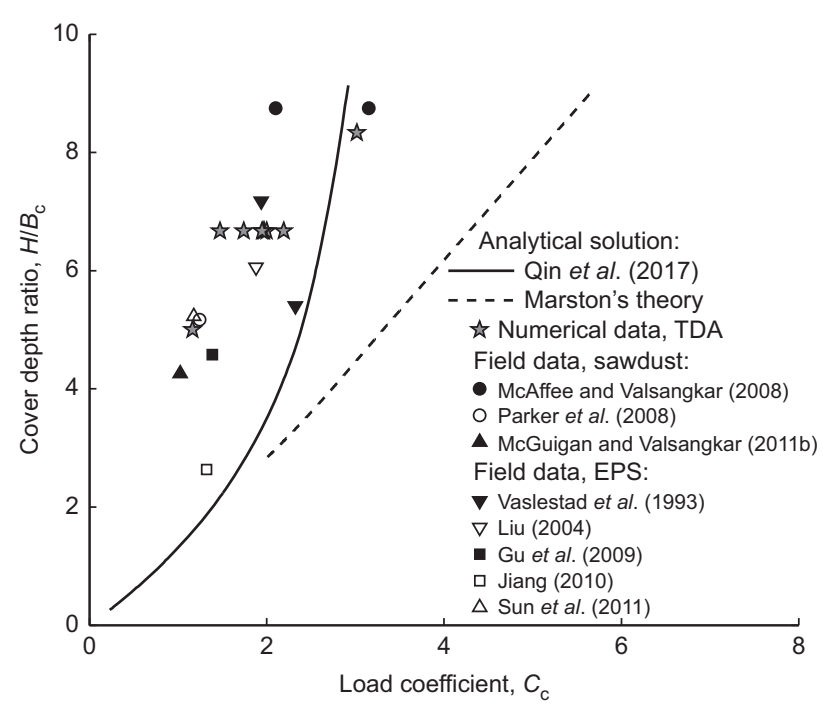

Figure 14. Comparison of load coefficient evaluated from numerical simulations for TDA, field measurements for other compressible materials and analytical solutions

of $C_{\mathrm{c}}$ for TDA generally coincide with the range of $C_{\mathrm{c}}$ obtained for other compressible materials at a different cover depth ratio $H / B_{\mathrm{c}}$. Almost all numerical data fall slightly on the left side of the prediction curve of Qin et al. (2017). It should be noted that the analytical solution of Qin et al. (2017) is dependent on the choice of relative stiffness between soil and TDA. The tangent modulus of TDA could range from 200-400 $\mathrm{kPa}$ based on the stress-strain curve in Figure 3. The prediction curve of Qin et al. (2017) in Figure 14 is calculated using an $E_{\mathrm{c}}$ of $300 \mathrm{kPa}$. Other choices of $E_{\mathrm{c}}$ value could potentially improve the analysis. In contrast, Marston's theory provides a prediction curve that is very conservative compared to field measurements and numerical data. Overall, the similar $C_{\mathrm{c}}$ values obtained for TDA compared to other compressible materials demonstrate that the numerical model in this investigation can reproduce experimental data measured in the field effectively. It is also indicated that existing analytical design approaches can still be used in design to provide a conservative estimate of earth pressure acting on an induced trench rigid pipe overlain by a TDA inclusion.

\section{CONCLUSIONS}

This investigation was conducted to evaluate the potential of using TDA as the compressible material for induced trench rigid pipes under the plane-strain condition. The numerical results for induced trench rigid pipes with TDA inclusions were also compared with field measurements for other compressible materials, as well as analytical calculations. The following conclusions can be drawn.

(1) The use of TDA in the compressible zone can provide similar beneficial effects on rigid pipes compared to other commonly used materials. With a TDA inclusion, the earth pressure is reduced significantly 
at the pipe crown and invert, but the lateral pressure at the springline is decreased slightly. Engineers in the area, where conventional compressible materials are not available but waste tires are abundant, could potentially choose TDA for their pipe installations.

(2) The earth pressures around the pipe reduce more with the increase in the width of the TDA zone, but do not change significantly with the variation of the thickness of TDA zone. A spacing of $0.2-0.3 \mathrm{~m}$ should be left between the pipe and the compressible zone, which can minimise the earth pressures.

(3) The efficiency of TDA in reducing earth pressures on the pipe is dependent on the relative stiffness between the soil and TDA. A higher relative stiffness between the soil and TDA could result in a more significant positive arching effect, which will cause more reduction of earth pressures.

(4) Numerical results of the load coefficient for TDA are generally consistent with the range measured in the field for other compressible materials. Existing analytical approaches are capable of conservatively designing an induced trench rigid pipe overlain by a TDA inclusion.

\section{NOTATION}

Basic SI units are given in parentheses.

$B_{\mathrm{c}} \quad$ pipe diameter $(\mathrm{m})$

$C_{\mathrm{c}}$ load coefficient (dimensionless)

$E_{\mathrm{c}}$ modulus of elasticity of the compressible material $(\mathrm{Pa})$

$E_{\mathrm{p}} \quad$ modulus of elasticity of pipe (Pa)

$E_{\mathrm{s}}$ modulus of elasticity of soil $(\mathrm{Pa})$

$H$ embankment elevation above the pipe (m)

$H_{\mathrm{e}} \quad$ height of the equal settlement plane (m)

$K \quad$ lateral earth pressure coefficient (dimensionless)

$K_{\mathrm{a}} \quad$ Rankine active earth pressure coefficient (dimensionless)

$K_{0} \quad$ lateral earth pressure coefficient at-rest (dimensionless)

$S \quad$ stress factor (dimensionless)

$s \quad$ spacing between the pipe and the compressible zone $(\mathrm{m})$

$t$ thickness of the compressible zone (m)

$w \quad$ width of the compressible zone (m)

$\alpha$ shape parameter (dimensionless)

$\beta$ force factor (dimensionless)

$\gamma_{\mathrm{c}}$ unit weight of the compressible material $\left(\mathrm{N} / \mathrm{m}^{3}\right)$

$\gamma_{\mathrm{p}}$ unit weight of pipe $\left(\mathrm{N} / \mathrm{m}^{3}\right)$

$\gamma_{\mathrm{s}}$ unit weight of soil $\left(\mathrm{N} / \mathrm{m}^{3}\right)$

$\mu$ friction coefficient (dimensionless)

$v_{\mathrm{c}} \quad$ Poisson's ratio of the compressible material (dimensionless)

$v_{\mathrm{p}} \quad$ Poisson's ratio of pipe (dimensionless)

$v_{\mathrm{s}} \quad$ Poisson's ratio of soil (dimensionless)

$\sigma_{\mathrm{v}} \quad$ vertical stress acting on the pipe $(\mathrm{Pa})$

\section{REFERENCES}

Abuhajar, O., Newson, T. \& El Naggar, H. (2015). Scaled physical and numerical modelling of static soil pressures on box culverts. Canadian Geotechnical Journal, 52, No. 11, 1637-1648.

ACPA (American Concrete Pipe Association) (2004). Concrete Pipe Design Manual, American Concrete Pipe Association, Vienna, VA, USA.

Ahmed, M. R., Tran, V. D. H. \& Meguid, M. A. (2015). On the role of geogrid reinforcement in reducing earth pressure on buried pipes: experimental and numerical investigations. Soils and Foundations, 55, No. 3, 588-599.

ASTM D6270 Standard Practice for Use of Scrap Tires in Civil Engineering Applications. ASTM International, West Conshohocken, PA, USA.

ASTM C655 Standard Specification for Reinforced Concrete D-Load Culvert, Storm Drain, and Sewer Pipe. ASTM International, West Conshohocken, PA, USA.

Bartlett, S. F., Lingwall, B. N. \& Vaslestad, J. (2015). Methods of protecting buried pipelines and culverts in transportation infrastructure using EPS geofoam. Geotextiles and Geomembranes, $\mathbf{4 3}$, No. $5,450-461$.

El Naggar, H., Turan, A. \& Valsangkar, A. (2015). Earth pressure reduction system using geogrid-reinforced platform bridging for buried utilities. Journal of Geotechnical and Geoenvironmental Engineering, 141, No. 6, 04015024.

Ertugrul, O. L. \& Trandafir, A. C. (2011). Reduction of lateral earth forces acting on rigid nonyielding retaining walls by EPS geofoam inclusions. Journal of Materials in Civil Engineering, 23, No. 12, 1711-1718.

GC (Geosyntec Consultants) (2008). Guidance Manual for Engineering Uses of Scrap Tires, Geosyntec Project No.: ME0012-11. Maryland Department of the Environmental Scrap Tire Programme, Columbia, MD, USA.

Gu, A. Q., Lv, Z. F., Jiang, F. L. \& Yang, Z. (2009). Load reduction tests and design methods for culverts with high fill soil using EPS slabs. Chinese Journal of Geotechnical Engineering, 31, No. 10, 1481-1486 (in Chinese).

Hegde, A. \& Sitharam, T. (2015). Experimental and numerical studies on protection of buried pipelines and underground utilities using geocells. Geotextiles and Geomembranes, 43, No. 5, 372-381.

Hunter, G. \& Fell, R. (2003). Rockfill modulus and settlement of concrete face rockfill dams. Journal of Geotechnical and Geoenvironmental Engineering, 129, No. 10, 909-917.

Jean, P. A. \& Long, N. T. (1990). Creation of arching (pneusol and other techniques). In Geotechnical Instrumentation in Practice: Purpose, Performance and Interpretation. Thomas Telford, London, UK, pp. $663-670$.

Jiang, F. L. (2010). EPS Load Reduction Technology Application and Numerical Simulation for High Fill Culvert, $\mathrm{PhD}$ thesis, Chang'an University, Xi'an, China (in Chinese).

Kang, J., Parker, F. \& Yoo, C. H. (2007). Soil-structure interaction and imperfect trench installations for deeply buried concrete pipes. Journal of Geotechnical and Geoenvironmental Engineering, 133, No. 3, 277-285.

Kang, J., Parker, F., Kang, Y. J. \& Yoo, C. H. (2008). Effects of frictional forces acting on sidewalls of buried box culverts. International Journal for Numerical and Analytical Methods in Geomechanics, 32, No. 3, 289-306.

Kawabata, T., Ling, H. I., Mohri, Y. \& Shoda, D. (2006). Behavior of buried flexible pipe under high fills and design implications. Journal of Geotechnical and Geoenvironmental Engineering, 132, No. 10, 1354-1359.

Kézdi, Á. (1974). Handbook of Soil Mechanics, Elsevier Scientific Publishing Company, Amsterdam, The Netherlands.

Kim, H., Choi, B. \& Kim, J. (2010). Reduction of earth pressure on buried pipes by EPS geofoam inclusions. Geotechnical Testing Journal, 33, No. 4, 304-313.

Lee, J., Salgado, R., Bernal, A. \& Lovell, C. (1999). Shredded tires and rubber-sand as lightweight backfill. Journal of Geotechnical and Geoenvironmental Engineering, 125, No. 2, 132-141. 
Liu, J. (2004). Study on the Earth Pressure Acting on the Culvert under the Embankment of High-staked Soil and the Load Reducing Technique, PhD thesis, Chang'an University, Xi'an, China (in Chinese).

Marston, A. (1922). Second Progress Report to the Joint Concrete Culvert Pipe Committee. Iowa Engineering Experimental Station, Ames, IA, USA.

McAffee, R. P. \& Valsangkar, A. J. (2004). Geotechnical properties of compressible materials used for induced trench construction. Journal of Testing and Evaluation, 32, No. 2, 1-10.

McAffee, R. P. \& Valsangkar, A. J. (2005). Performance of an induced trench installation. Transportation Research Record, 1936, 230-237.

McAffee, R. P. \& Valsangkar, A. J. (2008). Field performance, centrifuge testing, and numerical modelling of an induced trench installation. Canadian Geotechnical Journal, 45, No. 1, 85-101.

McGuigan, B. L. \& Valsangkar, A. J. (2010). Centrifuge testing and numerical analysis of box culverts installed in induced trenches. Canadian Geotechnical Journal, 47, No. 2, 147-163.

McGuigan, B. L. \& Valsangkar, A. J. (2011a). Earth pressures on twin positive projecting and induced trench box culverts under high embankments. Canadian Geotechnical Journal, 48, No. 2, 173-185.

McGuigan, B. L. \& Valsangkar, A. J. (2011b). Field monitoring and analysis of twin $3660 \mathrm{~mm}$ inside diameter induced trench culverts installed under $21.7 \mathrm{~m}$ of fill. Canadian Geotechnical Journal, 48 No. 5, 781-794.

McGuigan, B. L., Oshati, O. S., Parker, B. A. \& Valsangkar, A. J. (2016). Post-construction performance of induced trench rigid culverts. Canadian Geotechnical Journal, 53, No. 11, 1807-1821.

Meguid, M. A. \& Hussein, M. G. (2017). A numerical procedure for the assessment of contact pressures on buried structures overlain by EPS geofoam inclusion. International Journal of Geosynthetics and Ground Engineering, 3, No. 1, 2.

Meguid, M. A., Hussein, M., Ahmed, M., Omeman, Z. \& Whalen, J (2017a). Investigation of soil-geosynthetic-structure interaction associated with induced trench installation. Geotextiles and Geomembranes, 45, No. 4, 320-330.

Meguid, M. A., Ahmed, M. R., Hussein, M. G. \& Omeman, Z. (2017b). Earth pressure distribution on a rigid box covered with U-shaped geofoam wrap. International Journal of Geosynthetics and Ground Engineering, 3, No. 2, 11 .

Meguid, M. A. \& Youssef, T. A. (2018). Experimental investigation of the earth pressure distribution on buried pipes backfilled with tire-derived aggregate. Transportation Geotechnics, 14, 117-125.

Mehrjardi, G. T., Tafreshi, S. N. M. \& Dawson, A. R. (2012). Combined use of geocell reinforcement and rubber-soil mixtures to improve performance of buried pipes. Geotextiles and Geomembranes, 34, 116-130.

Mehrjardi, G. T., Tafreshi, S. N. M. \& Dawson, A. R. (2013) Pipe response in a geocell-reinforced trench and compaction considerations. Geosynthetics International, 20, No. 2, 105-118.

Meles, D., Bayat, A. \& Chan, D. (2014). One-dimensional compression model for tire-derived aggregate using large-scale testing apparatus. International Journal of Geotechnical Engineering, 8, No. 2, 197-204.

Meles, D., Chan, D., Yi, Y. \& Bayat, A. (2016). Finite-element analysis of highway embankment made from tire-derived aggregate. Journal of Materials in Civil Engineering, 28, No. 2, 04015100.

Mills, B. \& McGinn, J. (2010). Design, construction, and performance of a highway embankment failure repaired with tire-derived aggregate. Transportation Research Record, 2170, 90-99.

Moore, I. D. (2001). Buried pipes and culverts. In Geotechnical and Geoenvironmental Engineering Handbook, Rowe, R. K., Editor, Springer US, Kluwer Academic Publishers, Norwell, MA, USA, pp. 541-567.

Ni, P., Mei, G. \& Zhao, Y. (2017). Displacement-dependent earth pressures on rigid retaining walls with compressible geofoam inclusions: physical modeling and analytical solutions. International Journal of Geomechanics, 17, No. 6, 04016132.

Ni, P., Moore, I. D. \& Take, W. A. (2018). Numerical modeling of normal fault-pipeline interaction and comparison with centrifuge tests. Soil Dynamics and Earthquake Engineering, 105, 127-138.

Oshati, O. S., Valsangkar, A. J. \& Schriver, A. B. (2012). Earth pressures exerted on an induced trench cast-in-place double-cell rectangular box culvert. Canadian Geotechnical Journal, 49 , No. 11, 1267-1284.

Parker, B., McAffee, R. \& Valsangkar, A. (2008). Field performance and analysis of 3-m-diameter induced trench culvert under a 19.4-m soil cover. Transportation Research Record, 2045, 68-76.

Qin, X., Ni, P. \& Zhou, M. (2017). Improved analytical solution of vertical pressure on top of induced trench rigid culverts. Geosynthetics International, 24, No. 6, 615-624.

Rezaei, A., Kolahdouz, E. M., Dargush, G. F. \& Weber, A. S. (2012). Ground source heat pump pipe performance with tire derived aggregate. International Journal of Heat and Mass Transfer, 55 , No. 11, 2844-2853.

Rowe, R. K. \& McIsaac, R. (2005). Clogging of tire shreds and gravel permeated with landfill leachate. Journal of Geotechnical and Geoenvironmental Engineering, 131, No. 6, 682-693.

Shalaby, A. \& Khan, R. A. (2005). Design of unsurfaced roads constructed with large-size shredded rubber tires: a case study. Resources, Conservation and Recycling, 44, No. 4, 318-332.

Sladen, J. \& Oswell, J. (1988). The induced trench method-a critical review and case history. Canadian Geotechnical Journal, 25, No. 3, 541-549.

Spangler, M. G. (1968). Discussion of the modification of the pressures on rigid culverts with fill procedures. Highway Research Record, 249, 41-43

Sun, L. C., Hopkins, T. \& Beckham, T. (2011). Long-term monitoring of culvert load reduction using an imperfect ditch backfilled with geofoam. Transportation Research Record, 2212, 56-64.

Tien, H. J. (1996). A Literature Study of the Arching Effect, MSc thesis, Massachusetts Institute of Technology, Cambridge, MA, USA.

Turan, A., El Naggar, M. H. \& Dundas, D. (2013). Investigation of induced trench method using a full scale test embankment. Geotechnical and Geological Engineering, 31, No. 2, 557-568.

Vaslestad, J., Johansen, T. H. \& Holm, W. (1993). Load reduction on rigid culverts beneath high fills: long-term behavior. Transportation Research Record, 1415, 58-68.

Wartman, J., Natale, M. F. \& Strenk, P. M. (2007). Immediate and time-dependent compression of tire derived aggregate. Journal of Geotechnical and Geoenvironmental Engineering, 133, No. 3, 245-256.

Witthoeft, A. F. \& Kim, H. (2016). Numerical investigation of earth pressure reduction on buried pipes using EPS geofoam compressible inclusions. Geosynthetics International, 23, No. 4, 287-300.

Yang, S., Lohnes, R. A. \& Kjartanson, B. H. (2002). Mechanical properties of shredded tires. Geotechnical Testing Journal, 25, No. 1, 44-52.

Yi, Y., Meles, D., Nassiri, S. \& Bayat, A. (2015). On the compressibility of tire-derived aggregate: comparison of results from laboratory and field tests. Canadian Geotechnical Journal, 52, No. 4, 442-458.

Yoon, S., Prezzi, M., Siddiki, N. Z. \& Kim, B. (2006). Construction of a test embankment using a sand-tire shred mixture as fill material. Waste Management, 26, No. 9, 1033-1044.

Youwai, S. \& Bergado, D. T. (2003). Strength and deformation characteristics of shredded rubber tire - sand mixtures. Canadian Geotechnical Journal, 40, No. 2, 254-264.

Zornberg, J., Costa, Y. \& Vollenweider, B. (2004). Performance of prototype embankment built with tire shreds and nongranular soil. Transportation Research Record, 1874, 70-77.

The Editor welcomes discussion on all papers published in Geosynthetics International. Please email your contribution to discussion@geosynthetics-international.com by 15 April 2019. 